\title{
Correlation of refractive error with axial length and corneal topography
}

\author{
Poonam Kishore ${ }^{1}$, Vinita Singh ${ }^{1}$, Nitin Chaudhary ${ }^{2}$, Surabhi Ruia ${ }^{1}$ \\ 'Department of Ophthalmology, King George's Medical University, Lucknow, India; \\ ${ }^{2}$ Swastik Eyecare Centre, Unnao, India
}

\begin{abstract}
Purpose: To collect and analyze normative data about corneal topography and axial length in various refractive errors in Indian population.

Design: Cross-sectional observational study.

Materials and Method: Three hundred eyes (150 patients) of age group 12-35 yrs were arranged in 5 groups according to refractive status; Group 1 ( $n=44)$ : myopia of Spherical Equivalent (SE) > $6 D$; Group 2 ( $n=67)$ : myopia of $S E>0.5 D$ to $6 D$; Group 3 ( $n=88$ ): nearly emmetropic of SE -0.5 D to +0.5 D; Group $4(n=59)$ : hypermetropia of SE >0.5 to 6D; Group 5 ( $n=42)$ : hypermetropia of $S E>6 D$. Axial length $(A L)$, central radius of curvature of cornea $(C R)$, central power of cornea (CK), Al/CR ratio for each group were documented. Correlation with SE and among each other was studied.

Results: Mean AL (in $\mathrm{mm}$ ) of myopic patients ( $n=111$ ) was $24.23 \pm 1.34$, emmetropic ( $n=88$ ) $22.62 \pm 0.94$ and hypermetropics $(n=101) 20.73 \pm 0.94$. Mean CR (in mm) of myopic patients was $7.55 \pm 0.35$, emmetropics was $7.70 \pm 0.32$, and hypermetropes was $7.99 \pm 0.35$. Mean CK (in D) of myopics was 44.86 \pm 2.59 , emmetropes was $43.91 \pm 1.76$, and hypermetropes was $42.32 \pm 1.89$. Mean AL/CR ratio of myopics was $3.22 \pm 0.29$, emmetropics 2.94 \pm 0.07 , and hypermetropics $2.60 \pm 0.19$. AL was negatively correlated with $S E(r=-0.91$, $p<0.0001)$ and positively with $A L / C R(r=0.88, p<0.0001)$ and $C K(r=0.36, p<0.0001)$. CR was negatively correlated with $A L / C R(r=-0.74, p<0.0001)$ while positively correlated with $S E$ $(r=0.62, p<0.0001)$. CK showed positive correlation with $A L / C R(r=0.75, p<0.0001)$ while negative correlation with SE $(r=-0.61, p<0.0001)$. AL/CR was negatively correlated with $\operatorname{SE}(r=-0.95, p<0.0001)$.

Conclusion: This study showed a negative correlation between axial length and refractive error and between $A L / C R$ ratio and refractive error with stronger inverse relationship in hypermetropes than myopes. There was a positive correlation of $C R$ with $S E$ with a weaker direct relationship in myopes than hypermetropes.
\end{abstract}

Keywords: Axial length; central radius of curvature of cornea; corneal power; spherical equivalent.

\section{Introduction}

The refractive state or spherical equivalent(SE) of the eye is determined by refractive components (corneal power, lens power, anterior chamber depth, and axial length) which are interdependent rather than independent variables, and that the eye grows during the early years in life in such a manner that the refractive state tends towards emmetropia. ${ }^{1,2}$

Correspondence: Poonam Kishore, Department of Ophthalmology, King George's Medical University, Lucknow, India. 226003.

E-mail: poonam kishore2002@yahoo.com 
The axial length (AL) is the distance from the corneal surface to an interference peak corresponding to the retinal pigment epithelium ${ }^{3,4}$ and this is expressed in millimetres. Maximum eye growth takes place in the first 18 months of life after which there is little change, ${ }^{5}$ the majority of axial length elongation takes place in the first three to 6 months of life and a gradual reducing rate of growth over the next two years, ${ }^{6}$ and by three years the adult eye size is attained.

The cornea is the most powerful refracting surface of the eye, accounting for two-thirds of the eye's focusing power. The refractive power of the cornea (CK) depends on its curvature and the difference in refractive indices between it and air. $^{7}$ The interaction between axial length and corneal radius of curvature (CR) has played a major role in the compensatory adjustments of the optical components of the eye towards attaining emmetropic state. The axial length-corneal radius (AL/ $\mathrm{CR}$ ) ratio has been shown to give a better correlation with refractive error than is obtained with axial length alone..$^{8,9}$

\section{Materials and methods}

\section{Study subjects}

Our study had institutional review board clearance and was conducted as per the tenets of Helsinki declaration. A tertiary eye care centre based cross sectional observational study was conducted on hundred and fifty patients of the age group of 12-35 years. Data of three hundred eyes of these patients was stratified in 5 following groups, according to the refractive status: myopia of Spherical equivalent(SE) $>6 \mathrm{D}$; myopia of $\mathrm{SE}>0.5 \mathrm{D}$ to $-6 \mathrm{D}$; nearly emmetropic (-0.5 D to +0.5 D); hypermetropia of SE >0.5 D to + 6 D; hypermetropia of SE > + $6 \mathrm{D}$.

Patients who had other causes of diminution of vision such as cataract or posterior segment disease, those who had undergone cataract surgery, those who refused inclusion in the study, were all excluded from the study.

Refraction was done for each eye. Astigmatism was not an exclusion criteria and for all calculations and correlations SE was documented. Axial length (AL) documented by A-scan (Opticon). At least two readings were taken and the average calculated as the measured axial length. Corneal topography was done by Humphrey Atlas corneal topography system model 993, Atlas version A 12.1 (Carl Zeiss Meditec Inc., Dublin, CA, USA). Two reading from each eye was taken for Central corneal power $(\mathrm{CK})$ and Central radius of curvature $(\mathrm{CR})$. Simulated keratometry readings characterize corneal curvatures in the central $3 \mathrm{~mm}$ area. The simulated keratometry readings of steep and flat meridians of cornea were measured and average corrected corneal power in front of pupil (central power of cornea ) calculated by the software was documented.

Central radius of curvature of cornea was calculated by the formula $(k=0.3375 / r)$ where $k$ is the central power of cornea and $r$ is the central radius of curvature of cornea. 0.3375 is the difference in refractive indices of cornea and air.

Patients also underwent detailed slit lamp examination; fundus examination using direct ophthalmoscope (Welch Allyn 3. 5v Coaxial Ophthalmoscope), +90D 
Lens and indirect ophthalmoscope (IO-7 binocular indirect ophthalmoscope, Appaswami).

\section{Statistical Analysis}

Data were summarized as Mean \pm SD and percentage. The age and outcome measures ( $A L, C R, C K, A L / C R$ ratio) of five groups were compared by one way analysis of variance (ANOVA). The discrete (categorical) observations of sex of five groups were compared by chi-square $\left(x^{2}\right)$ test. Pearson correlation analysis was used to assess association between the variables. Linear regresion was used to find the strength of associations between two continuous variables. A two-sided $(a=2)$ $\mathrm{p}<0.05$ was considered statistically significant. All analyses were performed on STATISTICA (window version 6.0).

\section{Result}

On comparing the sex proportion (Male/Female), $X^{2}$ test revealed no significant difference in proportions of sex between the groups $\left(x^{2}=6.79 ; p=0.1473\right)$. The mean age of all groups show no significant difference $(F=0.27, p=0.8941)$.

SE of the five groups was summarized as Group 1: $-9.73 \pm 5.37$; Group 2: $-2.35 \pm$ 1.17; Group 3: $0.08 \pm 0.30 ;$ Group 4: $3.20 \pm 1.52 ;$ Group 5: $8.07 \pm 2.0$.

AL of the five groups was summarized as: Group 1: $25.25 \pm 1.49$; Group 2: 23.56 \pm 0.62; Group 3: $22.62 \pm 0.94$; Group 4: $21.28 \pm 0.71$; Group 5:19.97 \pm 0.64 . . Linear regression analysis of AL and SE: (Fig. 1) showed decrease in AL with increase in SE from myopia towards hypermetropia.

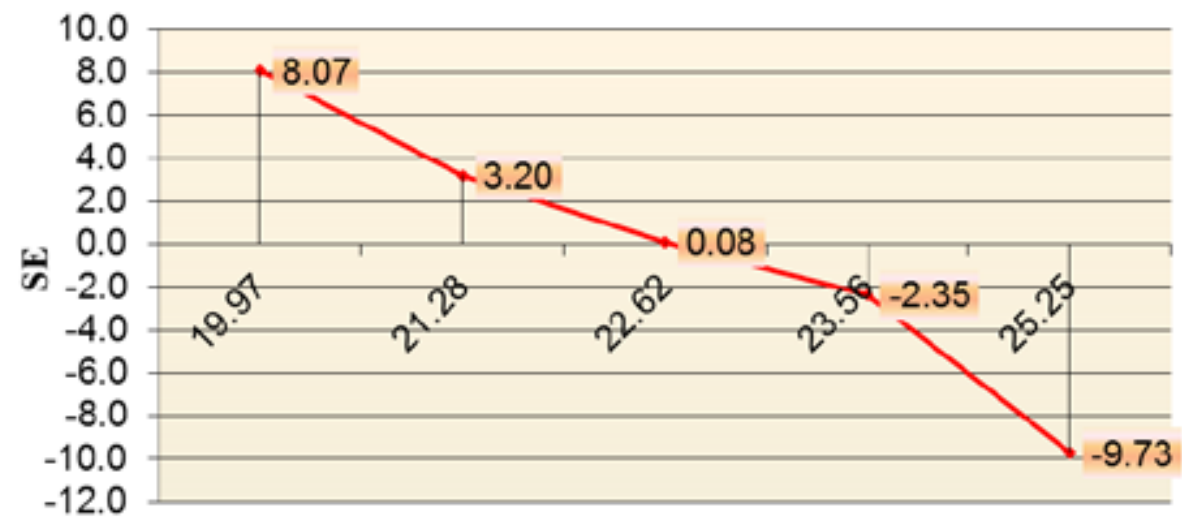

AL

Fig 1. Correlation between axial length (AL) and spherical equivalent (SE).

CR of the five groups was summarized as: Group 1: $7.46 \pm 0.44$; Group 2: $7.61 \pm$ 0.27; Group 3: $7.70 \pm$ 0.32; Group 4: $7.76 \pm$ 0.27; Group 5: $8.30 \pm 0.16$ Linear regression analysis between CR and SE: (Fig. 3) demonstrated increase in CR with change in SE from myopia to hypermetropia. 
CK of the five groups was summarized as: Group 1: $44.52 \pm 3.61$; Group 2: 44.42 \pm 1.48 ; Group 3: $43.91 \pm 1.76$; Group 4: $43.50 \pm 1.53$; Group 5: $40.66 \pm 0.77$. The data exemplified higher value of $\mathrm{CK}$ in myopes as compared to that in hypermetropes (Figure not shown).

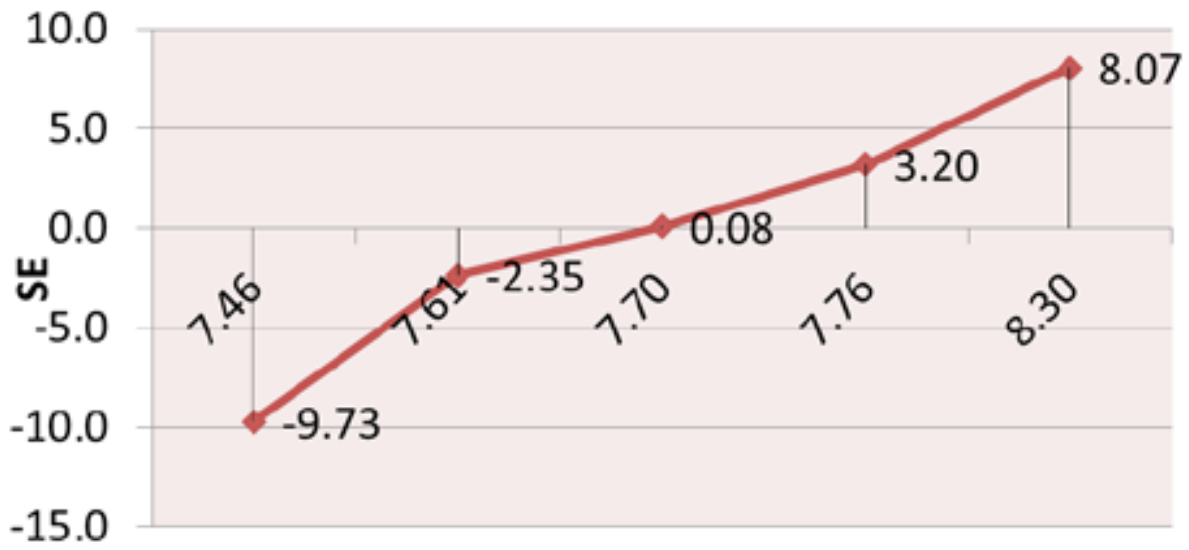

\section{CR}

Fig 2. Correlation between central radius of curvature of cornea (CR) and spherical equivalent.

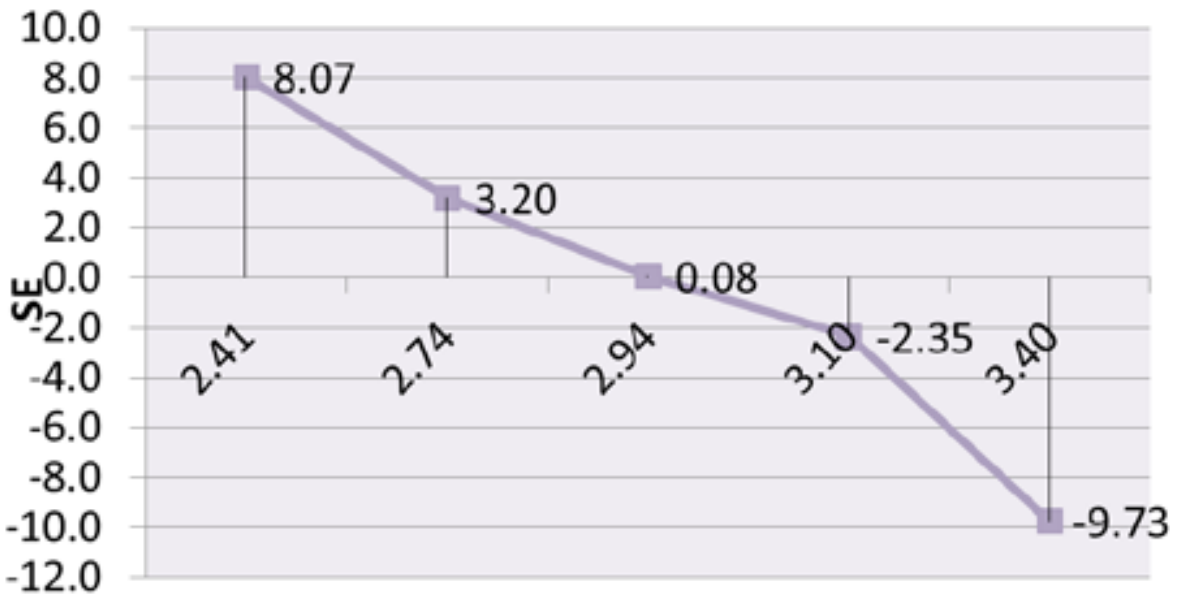

\section{$\mathrm{AL} / \mathrm{CR}$}

Fig 3. Correlation of $A L / C R$ ratio with Spherical equivalent.

$\mathrm{Al} / \mathrm{CR}$ of the five groups was summarized as: Group 1: $3.40 \pm 0.37 ;$ Group 2: 3.11 \pm 0.11; Group 3: $2.94 \pm$ 0.07; Group 4: $2.74 \pm 0.10$; Group 5: $2.41 \pm 0.08$. (Fig. 4) illustrates linear regression analysis between $\mathrm{AL} / \mathrm{CR}$ and $\mathrm{SE}$ i.e. as refractive status changes from myopic to hypermetropic side, $\mathrm{AL} / \mathrm{CR}$ ratio decreases. 
AL showed negative association with $C R(r=-0.37, p<0.0001)$ and SE $(r=-0.91$, $p<0.0001)$ while positive association with $C K(r=0.36, p<0.0001)$ and $A L / C R(r=0.88$, $p<0.0001)$. CR showed negative association with $C K(r=-0.98, p<0.0001)$ and $A L /$ $C R(r=-0.74, p<0.0001)$ while positive association with $S E(r=0.62, p<0.0001)$. CK showed positive association with $A L / C R(r=0.75, p<0.0001)$ while negative association with $S E(r=-0.61, p<0.0001)$. AL/CR ratio showed significantly high and negative association with $\mathrm{SE}(\mathrm{r}=-0.95, \mathrm{p}<0.0001)$. Table not shown.

Table 1 shows a higher correlation between $\mathrm{AL}$ and SE in myopes whereas in hypermetropes $C R$ and $A L / C R$ ratio had higher correlation with $S E$.

Table 2 summarizes the mean values of the study variables.

Table 1. Inter-correlation correlation among variables in myopes and hypermetropes.

\begin{tabular}{|l|l|l|l|}
\hline GROUP & AL & CR & AL/CR \\
\hline MYOPIA (N=111) & -0.86 & 0.51 & 0.91 \\
\hline HYPERMETROPIA (N=101) & -0.81 & 0.62 & 0.94 \\
\hline
\end{tabular}

Table 2. Mean values of study variables.

\begin{tabular}{|c|c|c|c|c|c|c|c|}
\hline & $\begin{array}{l}\text { GROUP } 1 \\
(n=44)\end{array}$ & $\begin{array}{l}\text { GROUP } 2 \\
(n=67)\end{array}$ & $\begin{array}{l}\text { GROUP } 3 \\
(n=88)\end{array}$ & $\begin{array}{l}\text { GROUP } 4 \\
(n=59)\end{array}$ & $\begin{array}{l}\text { GROUP } 5 \\
(n=42)\end{array}$ & $\begin{array}{l}\text { F VALUE } \\
(4,295 \text { DF })\end{array}$ & P VALUE \\
\hline SE & $\begin{array}{l}-9.73 \pm 5.37 \\
(-26.00 \text { to } \\
-6.25)\end{array}$ & $\begin{array}{l}-2.35 \pm \\
1.17 \\
(-5.75 \text { to } \\
-0.75)\end{array}$ & $\begin{array}{l}0.08 \pm 0.30 \\
(-0.50 \text { to } \\
0.50)\end{array}$ & $\begin{array}{l}3.20 \pm 1.52 \\
(1.00 \text { to } \\
5.50)\end{array}$ & $\begin{array}{l}8.07 \pm 2.05 \\
(6.50 \text { to } \\
13.50)\end{array}$ & 352.38 & $p<0.0001$ \\
\hline$A L$ & $\begin{array}{l}25.25 \pm \\
1.49 \\
(23.63 \text { to } \\
30.06)\end{array}$ & $\begin{array}{l}23.56 \pm \\
0.62 \\
(22.32 \text { to } \\
24.79)\end{array}$ & $\begin{array}{l}22.62 \pm \\
0.94 \\
(21.02 \text { to } \\
24.41)\end{array}$ & $\begin{array}{l}21.28 \pm \\
0.71 \\
(19.46 \text { to } \\
22.87)\end{array}$ & $\begin{array}{l}19.97 \pm \\
0.64 \\
(18.61 \text { to } \\
20.77)\end{array}$ & 231.79 & $p<0.0001$ \\
\hline CR & $\begin{array}{l}7.46 \pm 0.44 \\
(5.01 \text { to } \\
7.83)\end{array}$ & $\begin{array}{l}7.61 \pm \\
0.27 \\
(7.14 \text { to } \\
8.54)\end{array}$ & $\begin{array}{l}7.70 \pm 0.32 \\
(7.18 \text { to } \\
8.35)\end{array}$ & $\begin{array}{l}7.76 \pm 0.27 \\
(7.04 \text { to } \\
8.30)\end{array}$ & $\begin{array}{l}8.30 \pm 0.16 \\
(7.98 \text { to } \\
8.54)\end{array}$ & 48.54 & $p<0.0001$ \\
\hline CK & $\begin{array}{l}44.52 \pm \\
3.61 \\
(43.10 \text { to } \\
67.30)\end{array}$ & $\begin{array}{l}44.42 \pm \\
1.48 \\
(39.50 \text { to } \\
47.30)\end{array}$ & $\begin{array}{l}43.91 \pm \\
1.76 \\
(40.80 \text { to } \\
47.00)\end{array}$ & $\begin{array}{l}43.50 \pm \\
1.53 \\
(40.70 \text { to } \\
48.00)\end{array}$ & $\begin{array}{l}40.66 \pm \\
0.77 \\
(39.50 \text { to } \\
42.25)\end{array}$ & 37.33 & $p<0.0001$ \\
\hline AL/CR & $\begin{array}{l}3.40 \pm 0.37 \\
(3.14 \text { to } \\
5.06)\end{array}$ & $\begin{array}{l}3.11 \pm \\
0.11 \\
(2.86 \text { to } \\
3.27)\end{array}$ & $\begin{array}{l}2.94 \pm 0.07 \\
(2.77 \text { to } \\
3.07)\end{array}$ & $\begin{array}{l}2.74 \pm 0.10 \\
(2.60 \text { to } \\
3.02)\end{array}$ & $\begin{array}{l}2.41 \pm 0.08 \\
(2.25 \text { to } \\
2.51)\end{array}$ & 229.86 & $p<0.0001$ \\
\hline
\end{tabular}




\section{Discussion}

Mean SE of patients included in this study was $-0.17 \pm 5.64 \mathrm{D}$. Mean SE in myopic patients was $-5.27 \pm 5.02 \mathrm{D}$ and in hypermetropic patients was $5.20 \pm 3.0 \mathrm{D}$. Mean SE from group 1 to 5 was $-7.55 \pm 1.23 \mathrm{D},-2.35 \pm 1.17 \mathrm{D}, 0.08 \pm 0.30 \mathrm{D}, 3.16 \pm 1.50 \mathrm{D}$ and $8.08 \pm 2.08 \mathrm{D}$ respectively.

Mean AL of patients included in this study was $22.58 \pm 1.84 \mathrm{~mm}$. Mean AL of myopic patients was $24.23 \pm 1.34 \mathrm{~mm}$ and of hypermetropic patients was $20.73 \pm$ $0.94 \mathrm{~mm}$. Mean AL from group 1 to 5 was $24.78 \pm 0.84 \mathrm{~mm}, 23.61 \pm 0.69 \mathrm{~mm}, 22.62$ $\pm 0.94 \mathrm{~mm}, 21.29 \pm 0.71 \mathrm{~mm}$ and $19.96 \pm 0.64 \mathrm{~mm}$ respectively.

Tien Yin Wong et $\mathrm{al}^{10}$ in his study on chinese population in Singapore (2001) found the mean axial length of $23.23 \pm 1.17 \mathrm{~mm}$ slightly higher than our study. Elvis Ojaimi et $a^{11}$ in his study on Australian population (2005) in his study found nearly same mean axial length that was $22.61 \pm 0.02 \mathrm{~mm}$ (range: 19.64-25.35). Lourdes Llorente et $\mathrm{al}^{12}$ in their study on spanish population (2005) found lower AL $22.62 \pm 0.76 \mathrm{~mm}$ for hyperopic eyes and higher AL i.e $25.16 \pm 1.23 \mathrm{~mm}$ for myopic eyes.

Our study revealed a high correlation between $A L$ and SE $(r=-0.91, p<0.0001)$. This correlation was higher than previous studies. Correlation between AL and SE in myopic group $(r=-0.86, p<0.0001$, slope factor -4.9048$)$ was slightly higher than hypermetropic group ( $r=-0.81, p<0.0001$, slope factor -3.9944$)$.

Dr. Niall C et $a^{13}$ in his study in 1998 found significant, but lower than our study, relationship ( $r 2=0.611, p=0.0001$ ) between the degree of hyperopia and the measured AL. Stenstrom ${ }^{14}$ (1948) found the correlation between AL and SE to be -0.76 which was higher than other studies but lower than our study. Touzeau $O$ et $a l^{15}$ in their study on French population (2003) found a significant correlation between $A L$ and $S E(r=0.82, p<0.001)$. Jenny $M ~ I p$ et $a l^{16}$ in their study on Autralian population (2007) reported correlation of $(r=-0.44)$ between AL and SE in 6 year children and $(r=-0.61)$ in 12-year-old children.

Mean CK of patients included in this study was 43.72 $\pm 2.39 \mathrm{D}$. Mean CK of myopic patients was $44.86 \pm 2.59 \mathrm{D}$ and of hypermetropic patients was $42.33 \pm 1.90 \mathrm{D}$. Mean CK from group 1 to 5 was $45.52 \pm 0.81$ D, $44.42 \pm 1.48 \mathrm{D}, 43.91 \pm 1.76 \mathrm{D}, 43.49$ $\pm 1.53 \mathrm{D}$ and $40.67 \pm 0.78 \mathrm{D}$.

Sorsby et $a^{17}$ in their study on British population (1957), in their cross sectional study, reported mean CK of 43.25 D for emmetropic eyes and CK of 44.40 D for myopic eyes, and concluded that corneal power was probably as significant as axial length in production of ametropia upto 4.0 D.

Mean CK in female patients was found higher than male patients in emmetropic and hypermetropic subjects and vice versa in myopic subjects ( female $44.66 \pm 1.71$ $\mathrm{D}, 44.62 \pm 1.35 \mathrm{D}$ and $42.93 \pm 2.06 \mathrm{D}$, males $45.14 \pm 3.51 \mathrm{D}, 43.36 \pm 1.86 \mathrm{D}$ and 41.95 $\pm 1.69 \mathrm{D}$ for myopic, emmetropic and hypermetropic subjects respectively).

D Ganguli et $a^{18}$ (1975) 25 found average corneal power in emmetropic males was $43.57 \pm 0.08 \mathrm{D}$ and emmetropic females $44.13 \pm 0.12 \mathrm{D}$. Average corneal power in myopic males was found $43.78+0.10 \mathrm{D}$ and in myopic females was $45.29+0.11$ D. Average corneal power in hypermetropic males was found $43.08+0.12 \mathrm{D}$ and in hypermetropic females was $44.06+0.13 \mathrm{D}$. He found that corneal power was more 
in females than males whether the eyes are emmetropic, myopic or hypermetropic, but more marked in female myopes

Our study reveals a high correlation between CK and SE ( $r=-0.61, p<0.0001)$. Tahra Al Mahmoud et $\mathrm{al}^{19}$ in their study on Canadian population found a weaker relationship than our study $(\mathrm{r}=-0.18, \mathrm{P}<0.01)$.

Mean CR of patients included in this study was $7.74 \pm 0.39 \mathrm{~mm}$. Mean CR of myopic patients was $7.55 \pm 0.35 \mathrm{~mm}$ and of hypermetropic patients was $7.99 \pm 0.35$ $\mathrm{mm}$. Mean CR from group 1 to 5 was $7.59 \pm 0.16 \mathrm{~mm}, 7.61 \pm 0.27 \mathrm{~mm}, 7.70 \pm 0.32$ $\mathrm{mm}, 7.77 \pm 0.27 \mathrm{~mm}$ and $8.30 \pm 0.16 \mathrm{~mm}$.

Tien Yin Wong et $\mathrm{al}^{10}$ (2001) found the mean corneal curvature of $7.65 \pm 0.27 \mathrm{~mm}$. Lourdes Llorente et $\mathrm{al}^{12}$ (2005) found the radius of curvature of cornea in myopic eyes $(7.86 \pm 0.37 \mathrm{~mm})$ to be steeper than in hypermetropic eyes $(7.97 \pm 0.30 \mathrm{~mm})$. Elvis Ojaimi et al ${ }^{11}$ (2005) in his study found mean greatest CR was $7.85 \pm 0.01 \mathrm{~mm}$ and mean least $C R$ was $7.71 \pm 0.01 \mathrm{~mm}$.

Our study reveals a high correlation between CR and SE $(r=0.62, p<0.0001)$. Correlation between CR and SE in myopic group ( $r=0.51, p<0.0001$, slope factor 4.9048) was slightly lower than hypermetropic group ( $r=0.62, p<0.0001$, slope factor 3.9944). Jenny et $\mathrm{al}^{16}$ (2007) found lower correlation for SE with CR $(r \leq 0.09)$. Scott and Grosvenor ${ }^{20}$ in their study on population of America (1993) found a higher correlation between CR and SE $(r=+0.96)$. Dr. Niall C et al $^{13}$ (1998) found weak but statistically significant relationship $(r=0.128, p=0.009)$ between mean corneal radius measurements and mean spherical refractive errors, with mean corneal radius flattening with increasing hyperopia.

Our study reveals a negative correlation between $A L$ and $C R(r=-0.36, p<0.0001)$. Stenstrom ${ }^{14}$ (1948) found the correlation between AL and CR to be +0.18 , Hirsch et $a^{21}$ found the correlation to be +0.70 . Touzeau $O$ et $a^{15}$ (2003) found a strong correlation between $C R$ and $A L$ in emmetropic eyes $(r=0.63, p<0.001)$ and a weak but significant correlation in ametropic eyes $(r=0.28, p=0.002)$.

Mean AL/CR ratio of patients included in this study was $2.93 \pm 0.34$. Mean AL/CR ratio of myopic patients was $3.22 \pm 0.29$ and of hypermetropic patients was $2.60 \pm$ 0.19. Mean AL/CR ratio from group 1 to 5 was $3.27 \pm 0.07,3.11 \pm 0.11,2.94 \pm 0.07$, $2.74 \pm 0.10$ and $2.41 \pm 0.08$. Elvis Ojaimi et $a^{11}$ (2005) found distribution of axial length/mean corneal radius ratio was peaked (leptokurtic) with a mean of 2.91. Lourdes Llorente et $a^{12}$ (2005) found significantly $(p<0.0001)$ higher AL/CR ratio for myopic patients $(3.2 \pm 0.2)$ than in hyperopic patients $(2.8 \pm 0.1)$.

Our study reveals a high correlation between AL/CR ratio and SE $(r=-0.95$, $\mathrm{p}<0.0001$ ). The correlation between $\mathrm{AL} / \mathrm{CR}$ ratio with refractive status (Myopia $r=0.91, p<0.0001$, slope factor -4.9048 ; hypermetropia $r=0.94, p<0.0001$, slope factor -3.9944). The correlation in hypermetropic patients was slightly higher than myopic patients

Lourdes Llorente et $a l^{12}$ (2005) found a highly significant correlation between AL/CR and refractive error $\mathrm{SE}(\mathrm{p}<.0001, \mathrm{r}=-0.93$, slope $=-0.058)$ which was almost similar to our study. They found higher correlation for myopes $(p<.0001, r=0.87$, slope $=-0.07)$ than hyperopes $(p<.0001, r=0.7171$, slope $=-0.04)$ which was contrary to our study. 
An attempt was further made to study the role of $A L$ and $C R$ in various refractive errors with emmetropic patients. The corneal radius was more or less than \pm 1 SD different from mean emmetropic eyes in $20.72 \%$ in myopes and $53.48 \%$ of hypermetropes. The corresponding figures for axial length variations are $67.57 \%$ in myopes and $85.15 \%$ in hypermetropes. Thus, indicating a significant role of AL in higher population of patients. Corneal radius had a similar role in $3.60 \%$ of myopes and $50.54 \%$ of hypermetropes. AL was found to be causative factor in $67.56 \%$ of myopes and $85 \%$ of hypermetropes.

It is evident from above discussion that axial length plays very important role in causation of refractive errors, while corneal radius plays so in causation of hypermetropia. In our best knowledge, no such type of comparison was made in past studies.

The differences across studies may be due to several reasons: different age groups, refractive error ranges, and populations and ethnicities, differences in the statistical power of the studies, and differences across methods of measurement of $\mathrm{CR}, \mathrm{AL}$, SE and CK.

\section{Conclusion}

This study reveals a highly significant correlation between axial length and spherical equivalent, the correlation being slightly higher in myopic group than hypermetropic group.

A significant correlation between central power of cornea and spherical equivalent was found. This study reveals a high correlation between central radius curvature of cornea and spherical equivalent. Correlation between central radius curvature of cornea and spherical equivalent in myopic group was slightly lower than hypermetropic group.

A significant correlation between AL/CR ratio and spherical equivalent was found. The correlation in hypermetropic patients was slightly higher than myopic patients.

Our study is distinct owing to paucity of studies reported in Indian population on analysis of normative data correlating optical biometry parameters with refractive error. This study corroborates with findings of similar studies carried out in other population.

\section{References}

1. Mutti DO, Mitchell GL, Jones LA, et al. Axial Growth and Changes in Lenticular and Corneal Power during Emmetropization in Infants. Invest Ophthalmol Vis Sci. 2005;46(9):074-3080.doi: 10.1167/ iovs.04-1040.

2. Pennie FC, Wood ICJ, Olsen C, White S, Charman WN. A longitudinal study of the biometric and refractive changes in full-term infants during the first year of life.Ophthalmology. 1995 ;102(5):82730. doi:10.1016/S0042-6989(01)00169-9

3. Hitzenberger CK. Optical measurement of the axial eye length by laser Doppler interferometry. Invest Ophthalmol Vis Sci. 1991;32(3);616-624.

4. Schmid GF, Papastergiou GI, Nickla DL et al.Validation of laser Doppler interferometric measurements in vivo of axial eye length and thickness of fundus layers in chicks. Current Eye Research 1996; 15(6), 691-696. 
5. Flitcroft DI, Knight-Nanan D, Bowell R, Lanigan B, \& O'Keefe M. Intraocular lenses in children: changes in axial length, corneal curvature, and refraction. $\mathrm{Br} J$ Ophthalmol. 1999; 83(3): 265-269. doi:10.1136/bjo.83.3.265.

6. Gordon RA, Donzis PB. Refractive development of the human eye. Arch Ophthalmol.1985;103(6):785-789. doi:10.1001/archopht.1985.01050060045020.

7. Waltman SR and Hart WM. The cornea in Adler's Physiology of the Eye-Clinical Application( R. A. Moses and W. M. Hart) Eds., pp. 36-59, CV Mosby Coy, St. Louis, Mo, USA, 8th edition, 1987.

8. Iyamu E, lyamu J, Obiakor Cl. The Role of Axial Length-Corneal Radius of Curvature Ratio in Refractive State Categorization in a Nigerian Population. ISRN Ophthalmology. 2011. doi: $10.5402 / 2011 / 138941$.

9. Grosvenor T, Scott R. Role of the axial length/corneal radius ratio in determining the refractive state of the eye. Optometry and Vision Science. 1994; 71(9): 573-579.

10. Wong T.Y, Foster P.J , Ng T.P, et al. Variations in Ocular Biometry in an Adult Chinese Population in Singapore: The Tanjong Pagar Survey. Invest. Ophthalmol. Vis. Sci. 2001; 42:1 73-80.

11. Ojaimi E, Rose K.A, Morgan I.G, et al . Distribution of Ocular Biometric Parameters and Refraction in a Population-Based Study of Australian Children. Invest. Ophthalmol. Vis. Sci.2005;46(8):27482754. doi: 10.1167/iovs.04-1324.

12. Llorente L, Barbero S, Cano D, Dorronsoro C \& Marcos S. Axial length, corneal shape and optical aberrations in myopic versus hyperopic eyes. Journal of Vision. 2003;3(12). doi: 10.1167/3.12.27.

13. Strang NC, Schmid KL, Carney LG. Hyperopia is predominantly axial in nature. Current Eye Research. 1998;17(4):380-383. doi:10.1080/02713689808951218.

14. Stenstrom S, "Investigation of the variation and correlation of the optical elements of human eyes," American Journal of Optometry \& Archives of American Academy of Optometry, 1949;25:496-504.

15. Touzeau O, Allouch C, Borderie V, et al. Correlation between refraction and ocular biometry. Journal Francais D'ophtalmologie 2003, 26(4):355-363. PMID:12843892.

16. JM Ip, Huynh S.C, Kifley A, et al. Variation of the Contribution from Axial Length and Other Oculometric Parameters to Refraction by Age and Ethnicity. Invest. Ophthalmol. Vis. Sci. 2007;48(10):4846-4853. doi: 10.1167/iovs.07-0101.

17. Sorsby, Arnold, B. Benjamin, et al. “Emmetropia and its aberrations. Medical Research Council Special Report Series no 293." (1957).

18. D Ganguli, IS Roy, SK Biswas, M Sengupta. Study of corneal power and diameter in simple refractive error. Indian journal of ophthalmology 1975;23(1):6-11.

19. AlMahmoud T, Priest D, Munger R. Correlation between Refractive Error, Corneal Power, and Thickness in a Large Population with a Wide Range of Ametropia. Invest. Ophthalmol. Vis. Sci. 2011; 52(3):1235-1242. doi: 10.1167/iovs.10-5449.

20. Grosvenor T, Scott $\mathrm{R}$, "Role of the axial length/corneal radius ratio in determining the refractive state of the eye," Optometry and Vision Science, 1994; 71: 573-579.

21. Hirsch, Monroe J and Weymouth F.W. Notes on ametropia; a further analysis of Stenstrom's data. American journal of optometry and archives of American Academy of Optometry 1947;24(12): 601-608. 